\title{
Densidade de estocagem de larvas de mandi-pintado (Pimelodus britskii)
}

\author{
Stocking density of Pimelodus britskii larvae
}

\author{
Jakeline Marcela Azambuja de Freitas ${ }^{[\mathrm{a}]}$, Cesar Sary ${ }^{[\mathrm{b}]}$, Joana Karin Finkler ${ }^{[\mathrm{c}]}$, \\ Micheli Zaminham ${ }^{[\mathrm{d}]}$, Aldi Feiden ${ }^{[\mathrm{e}]}$, Wilson Rogério Boscolo ${ }^{[\mathrm{f}]}$
}

[a] Acadêmica de Engenharia de Pesca da UNIOESTE, Toledo, Paraná - Brasil, e-mail: jakelinemarcela@ibest.com.br

[b] Zootecnista, técnico do Centro de Produção e Propagação de Organismos Marinhos (CPPOM) da Pontifícia Universidade Católica do Paraná (PUCPR), Guaratuba, Paraná - Brasil, e-mail: zitozootecnia@hotmail.com

[c] Acadêmica de Engenharia de Pesca da UNIOESTE, Toledo, Paraná - Brasil, e-mail: joana_jkf@hotmail.com

[d] Acadêmica de Engenharia de Pesca da UNIOESTE, Toledo, Paraná - Brasil, e-mail: michelizam@hotmail.com

[e] Engenheiro agrônomo, Doutor em Ecologia de Ambientes Aquáticos Continentais, professor adjunto da Universidade Estadual do Oeste do Paraná (UNIOESTE), Toledo, Paraná - Brasil, e-mail: feiden@seti.pr.gov.br

[f Zootecnista, Doutor em Produção Animal, professor adjunto da Universidade Estadual do Oeste do Paraná (UNIOESTE), Toledo, Paraná - Brasil, e-mail: wrboscolo@bol.com.br

\section{Resumo}

O objetivo do presente trabalho foi avaliar a influência da densidade de estocagem sobre o desempenho produtivo e a sobrevivência de larvas de mandi-pintado (Pimelodus britskii). Foram utilizadas 452 larvas de mandis distribuídas inteiramente ao acaso em 16 aquários com capacidade para $30 \mathrm{~L}$ de volume útil. O delineamento utilizado foi inteiramente casualizado com quatro tratamentos $(0,25 ; 0,5 ; 1$ e 2 larvas $\mathrm{L}^{-1}$ ) e quatro repetições. A alimentação constituiu-se de náuplios de Artemia sp., sendo esta substituída gradativamente por ração contendo $45 \%$ de proteína bruta $(\mathrm{PB})$. As variáveis avaliadas foram peso final, comprimento final e sobrevivência. Ao final do experimento, observou-se que o aumento da densidade de estocagem afetou o crescimento das larvas, não sendo evidenciadas diferenças significativas $(\mathrm{p}>0,05)$ em relação à sobrevivência, com valores médios variando de $98,333 \%$ a $85,000 \%$ entre tratamentos. Conclui-se que a taxa de estocagem de 0,5 larvas $\mathrm{L}^{-1}$ proporciona melhores resultados de desempenho produtivo e sobrevivência para larvas de mandi-pintado.

Palavras-chave: Espécie nativa. Larvicultura. Manejo. Piscicultura. 


\begin{abstract}
This study aimed to evaluate the influence of stocking density $(0.25 ; 0.5 ; 1$ and 2 larvae/L) on the performance and survival of Pimelodus britskii larvae. It was used 452 larvae distributed randomly in 16 tanks with $30 \mathrm{~L}$ of useful volume. The feeding consisted in Artemia sp., which was gradually replaced by a diet containing $45 \%$ crude protein (PC).The variables analyzed were final weight, final length and survival. At the end of the experiment, it was observed that the larvae growth was affected according to the stocking density increase, but significant differences $(p>0,05)$ regarding to survival were not observed. It was concluded that the P. britskii larvae stocked at the density 0.05 larvae/L provides better results in productive performance and survival.
\end{abstract}

Keywords: Growth. Hatchery. Handling. Native species.

\title{
Introdução
}

A piscicultura brasileira é uma atividade que vem se destacando de forma significativa dentre os vários setores de produção animal do país (AMARAL et al., 2008). Nesse sentido, estudos relacionados aos fatores que podem aprimorar os sistemas de criação (LUZ; PORTELLA, 2005) são importantes para o incremento da atividade.

A densidade de estocagem é um dos fatores que tem merecido maior atenção na larvicultura de peixes (CAMPAGNOLO; NUÑER, 2006). A importância deste fator diz respeito à sua influência sobre o desempenho produtivo dos animais, uma vez que pode afetar o crescimento (HATZIATHANASIOU et al., 2002), a sobrevivência (KESTEMONT et al., 2003) e influenciar no comportamento das larvas (BASKERVILLEBRIDGES; KLING, 2000).

Normalmente, peixes criados em baixas densidades de estocagem apresentam boa taxa de crescimento e alta porcentagem de sobrevivência (BRANDÃO et al., 2005). No entanto, a utilização de quantidades reduzidas de animais leva a uma subutilização do espaço disponível (LUZ; SANTOS, 2008). Em contrapartida, a utilização de densidades elevadas, em princípio uma opção promissora que combina o máximo uso da água com maior produção de peixes (URBINATI; CARNEIRO, 2004), pode ser prejudicial, acarretando a redução da sobrevivência e produtividade final dos peixes (LUZ; ZANIBONI FILHO, 2002; ANDRADE et al., 2004; CAMPAGNOLO; NUÑER, 2006).

Dessa forma, o conhecimento das taxas máximas de estocagem é importante, já que a utilização da densidade adequada se torna uma operação benéfica comercialmente, pois infere na determinação dos custos de produção, bem como permite otimizar a produtividade dos sistemas de cultivo (KRUMMENAUER et al., 2006).

$\mathrm{Na}$ larvicultura intensiva, além da densidade, a qualidade do alimento a ser fornecido também é fundamental para o sucesso da atividade. Náuplios de Artemia sp. podem ser oferecidos às larvas de peixes, desde a primeira alimentação, com boa aceitação das várias espécies de água doce (LUZ; ZANIBONI FILHO, 2001; JOMORI et al., 2003; LUZ; PORTELLA, 2005; FEIDEN; HAYASHI; BOSCOLO, 2006). Entretanto, o alto custo associado à baixa sobrevivência do microcrustáceo em água doce, o que o torna menos disponível para a alimentação das larvas (WEINGARTNER; ZANIBONI FILHO, 2004), tem contribuído para a utilização do alimento vivo em associação com dietas artificiais para possibilitar, dessa forma, a otimização da produção de larvas de peixes (LUZ, 2004).

O mandi-pintado (P. britskii) é uma espécie descrita recentemente no Rio Iguaçu na drenagem do Rio Paraná, na divisa dos Estados do Paraná e Santa Catarina. Caracteriza-se pelo padrão de colorido, com máculas arredondadas dispersas, regularmente no tronco (GARAVELLO; SHIBATTA, 2007). Os autores descrevem-na como sendo endêmica à bacia do Rio Iguaçu e nela se posicionando como a segunda espécie do gênero Pimelodus.

O desenvolvimento de tecnologias para a criação de espécies autóctones é de fundamental importância para o aprimoramento da piscicultura. No Rio Iguaçu, onde o endemismo chega a 80\% (AGOSTINHO et al., 2002), o fomento à criação de espécies endêmicas é condição necessária para evitar a introdução de espécies

Rev. Acad., Ciênc. Agrár. Ambient., Curitiba, v. 8, n. 4, p. 389-396, out./dez. 2010 
alóctones em produções comerciais, as quais podem causar depleção ou mesmo extinção de estoques nativos, gerando impactos ambientais de grandes consequências (PIEDRAS; POUEY; MORAES, 2006).

Nesse contexto, o objetivo do presente trabalho foi avaliar o efeito da densidade de estocagem sobre o desempenho produtivo e a sobrevivência de larvas de mandi-pintado (P. britskii).

\section{Materiais e métodos}

O experimento foi realizado no Laboratório de Aquicultura da Unioeste - Câmpus de Toledo, durante um período experimental de 20 dias. Foram utilizadas 452 larvas de mandi-pintado ( $P$. britskii) - com peso inicial médio de 3,3 \pm 1,5 mg e comprimento médio inicial de $8,41 \pm 0,96 \mathrm{~mm}$-, distribuídas em 16 aquários com capacidade para $30 \mathrm{~L}$ de volume útil. Elas receberam aeração constante por meio de um sistema ligado a um soprador central e fotoperíodo natural. A água dos aquários foi renovada diariamente com troca de aproximadamente $30 \%$ do volume, sendo nesse momento realizada a sifonagem para a retirada de sobras de alimentos e fezes.

O delineamento utilizado foi inteiramente casualizado com quatro tratamentos e quatro repetições. As densidades de estocagem avaliadas foram de 0,25; 0,5; 1 e 2 larvas $\mathrm{L}^{-1}$. A alimentação foi realizada quatro vezes ao dia $(8 \mathrm{~h}, 11 \mathrm{~h}, 14 \mathrm{~h}$ e $17 \mathrm{~h})$ até a saciedade aparente. A ração foi fornecida em conjunto com náuplios de Artemia sp. durante quatro dias, sendo posteriormente substituída gradativamente por ração farelada até o $8^{\circ}$ dia de experimento, após tal período passaram a receber somente alimento inerte.

As larvas foram obtidas a partir de reprodução induzida. Os ovos foram incubados em incubadoras cônico-cilíndricas de $90 \mathrm{~L}$, mantidos em fluxo contínuo de água e fotoperíodo natural. Após o início da alimentação exógena, as larvas passaram a receber náuplios de Artemia sp. durante o período de sete dias. Posteriormente, as larvas foram transferidas para as unidades experimentais, o que caracterizou o início do experimento.

Para a eclosão dos cistos de Artemia sp. foram utilizadas incubadoras com capacidade para $1 \mathrm{~L}$ de água, dotadas de aeração constante, abastecidas com água com salinidade de 50\%, mantidas sob iluminação e temperatura de $28{ }^{\circ} \mathrm{C}$. Após a eclosão, realizou-se filtragem em malha de $20 \mu \mathrm{m}$ e posteriormente os náuplios foram fornecidos às larvas. A ração foi formulada de forma a conter 45\% de PB (Tabela 1). Os ingredientes que a compõem foram moídos em um triturador tipo martelo com peneira $0,7 \mathrm{~mm}$, pesados, misturados manualmente, acrescidos do suplemento mineral e vitamínico, e depois essa mistura foi fornecida na forma farelada.

Os parâmetros físicos e químicos da água, como $\mathrm{pH}$, condutividade elétrica $\left(\mathrm{mS} \mathrm{cm}^{-1}\right)$ e oxigênio dissolvido $\left(\mathrm{mg} \mathrm{L}^{-1}\right)$, foram monitorados semanalmente, e a temperatura da água $\left({ }^{\circ} \mathrm{C}\right)$ foi mensurada diariamente no período da manhã e à tarde.

Tabela 1 - Composição química da ração experimental fornecida às larvas de mandi-pintado (Pimelodus britski) durante a fase inicial de desenvolvimento

(continua)

\begin{tabular}{lc}
\hline Ingredientes & $\%$ \\
\hline Antioxidante (BHT) & 0,020 \\
Fosfato bicálcico & 0,458 \\
Farelo de soja & 34,578 \\
Farinha de peixe & 28,678 \\
Farinha de vísceras de aves & 20,000 \\
Hidrolisado de fígado & 3,000
\end{tabular}

Rev. Acad., Ciênc. Agrár. Ambient., Curitiba, v. 8, n. 4, p. 389-396, out./dez. 2010 
Tabela 1 - Composição química da ração experimental fornecida às larvas de mandi-pintado (Pimelodus britski) durante a fase inicial de desenvolvimento

(conclusão)

\begin{tabular}{lr}
\hline Ingredientes & $\%$ \\
\hline Óleo de soja & 10,966 \\
Suplemento mineral e vitamínico ${ }^{1}$ & 2,000 \\
Sal comum & 0,300 \\
\hline Total & 100,000 \\
\hline Nutrientes & $\%$ \\
\hline Amido & 0,000 \\
Cálcio & 2,392 \\
Energia digestível (kcal/kg) & 3750,045 \\
Fibra bruta & 2,432 \\
Fósforo total & 1,500 \\
Gordura & 15,551 \\
Histidina & 1,041 \\
Lisina total & 2,825 \\
Met + Cistina total & 1,567 \\
Metionina total & 0,951 \\
Proteína digestível & 24,987 \\
Proteína bruta & 45,000 \\
Treonina total & 1,884 \\
Triptofano & 0,483 \\
\hline
\end{tabular}

${ }^{1}$ Níveis de garantia por $\mathrm{kg}$ do produto - Premix (DSM-Roche $\left.{ }^{\circledR}\right)$ : Vit. A: 24.000 UI; Vit. D3: 6.000 UI; Vit. E: 300 mg; Vit. K3: 30 mg; Vit. B1: 40 mg; Vit. B2: 40 mg; Vit. B6: 35 mg; Vit. B12: 80 mg; Ác. fólico: 12 mg; Pantotenato Ca: 100 mg; Vit. C: 600 mg; Biotina: 2 mg; Colina: 1.000 mg; Niacina; Ferro: 200 mg; Cobre: 35 mg; Manganês: 100 mg; Zinco: 240 mg; Iodo: 1,6 mg; Cobalto: 0,8 mg.

Fonte: Elaboração dos autores.

Ao fim do experimento, as larvas foram pesadas e medidas para determinação do peso final, comprimento final, fator de condição [(peso final/comprimento final^3)*100], taxa de crescimento específico [(ln do peso final - ln peso inicial)/tempo em dias)*100] e sobrevivência. As taxas de sobrevivência sofreram transformação prévia por meio da expressão $\mathrm{y}=\operatorname{arcsen} \sqrt{(\mathrm{x} / 100)}$, sendo x o valor obtido para a sobrevivência em percentagem, para posterior análise estatística. 
Os resultados obtidos foram submetidos ao teste de homogeneidade, normalidade e análise de variância ANOVA, software STATISTICA (StatSoft $\left.{ }^{\circledR}, 2004\right)$, e quando foram observadas diferenças significativas foi aplicado o teste de comparação de médias Tukey $(\mathrm{p}<0,05)$.

\section{Resultados e discussões}

A temperatura da água apresentou valores médios de $24,95 \pm 0,82\left({ }^{\circ} \mathrm{C}\right)$ para o período da manhã e 24,63 \pm 0,66 $\left({ }^{\circ} \mathrm{C}\right)$ para o período da tarde. $\mathrm{O} \mathrm{pH}$, oxigênio dissolvido $\left(\mathrm{mg} \mathrm{L}^{-1}\right)$ e a condutividade elétrica $\left(\mathrm{mS} \mathrm{cm}^{-1}\right)$ apresentaram médias de 8,01 \pm 0,20; 5,54 $\pm 0,32$ e 0,22 $\pm 0,29$, respectivamente. Os resultados obtidos permaneceram dentro da faixa recomendada para o cultivo de peixes tropicais (BOYD, 1990). Os valores médios dos parâmetros de desempenho produtivo das larvas de mandi-pintado criadas em diferentes densidades de estocagem estão apresentados na Tabela 2.

Tabela 2 - Valores de desempenho de mandis P. britskii criados em diferentes densidades

\begin{tabular}{|c|c|c|c|c|}
\hline \multirow{2}{*}{ Parâmetros } & \multicolumn{4}{|c|}{ Densidade (larvas/L) } \\
\hline & 0,25 & 0,5 & 1 & 2 \\
\hline $\mathrm{PF}(\mathrm{g})$ & $0,148 \pm 0,02 \mathrm{ab}$ & $0,152 \pm 0,02 \mathrm{a}$ & $0,112 \pm 0,01 b$ & $0,114 \pm 0,02 \mathrm{ab}$ \\
\hline $\mathrm{CF}(\mathrm{cm})$ & $2,605 \pm 0,10 a$ & $2,631 \pm 0,09 a$ & $2,349 \pm 0,03 b$ & $2,340 \pm 0,15 b$ \\
\hline $\mathrm{SO}(\%)$ & $90,625 \pm 11,97 a$ & $98,333 \pm 3,33 a$ & $85,000 \pm 12,91 \mathrm{a}$ & $85,000 \pm 4,91 \mathrm{a}$ \\
\hline $\mathrm{FC}(\%)$ & $0,839 \pm 0,08 a$ & $0,832 \pm 0,07 a$ & $0,864 \pm 0,06 a$ & $0,883 \pm 0,04 a$ \\
\hline TCE $(\%)$ & $19,000 \pm 0,62 \mathrm{ab}$ & $19,114 \pm 0,58 \mathrm{a}$ & $17,615 \pm 0,33 b$ & $17,654 \pm 1,03 b$ \\
\hline
\end{tabular}

Legenda: Médias na mesma linha seguidas de letras distintas diferem pelo teste de Tukey a 5\%. NS = não significativo. $\mathrm{PF}=$ peso final $\mathrm{CF}=$ comprimento final; $\mathrm{SO}=$ sobrevivência $; \mathrm{FC}=$ fator de condição; $\mathrm{TCE}=$ taxa de crescimento específico.

Fonte: Elaboração dos autores.

Os resultados obtidos permitem estabelecer que, em relação ao peso final, a densidade de estocagem de 0,5 larvas $\mathrm{L}^{-1}$ mostrou-se estatisticamente superior $(0,152 \mathrm{~g})$ em relação à densidade de 1 larva $\mathrm{L}^{-1}(0,112$ g), porém não diferiu dos demais tratamentos $\left(0,25\right.$ e 2 larvas $\left.\mathrm{L}^{-1}\right)$. Esses valores diferem daqueles observados por Andrade et al. (2004), que encontraram redução linear no peso final, em função do aumento da densidade de estocagem, trabalhando com larvas de Pseudoplatystoma corruscans (14, 28, 42 e 56 larvas L $\left.{ }^{-1}\right)$. Luz e Zaniboni Filho (2002), avaliando as densidades de 5, 15 e 30 pós-larvas $\mathrm{L}^{-1}$ na larvicultura do mandi-amarelo (Pimelodus maculatus) também obtiveram maiores valores de peso final $(0,25 \mathrm{mg})$ nas larvas criadas em menor densidade.

Em relação ao comprimento final total, as larvas mantidas nas menores densidades de estocagem $\left(0,25\right.$ e 0,5 larvas $\left.\mathrm{L}^{-1}\right)$ mostraram-se superiores aos demais tratamentos. Segundo Jobling (1994), o aumento da densidade de estocagem é um fator que pode afetar o crescimento dos peixes, ocasionando alterações comportamentais em razão das interações sociais.

No entanto, Luz e Portella (2005) não evidenciaram diferenças significativas entre o comprimento total e o peso na larvicultura do trairão Hoplias lacerdae estocado nas densidades de 10, 30, 60 e 90 larvas L ${ }^{-1}$. Resultado semelhante também foi encontrado por Campagnolo e Nuñer (2006) em que, avaliando as densidades de 15, $35,55,75$ e 95 larvas $\mathrm{L}^{-1}$ de surubim $P$. corruscans criado em aquários com volume útil de $5 \mathrm{~L}$ e água salinizada a $5 \%$, observaram ausência de relação entre a densidade de estocagem e as variáveis de peso e comprimento final. 
Embora a maioria dos relatos se reporte a efeitos negativos das altas densidades de estocagem, o mecanismo de resposta do peixe para determinada densidade varia amplamente entre as espécies (CAMPAGNOLO; NUÑER, 2006), condições de criação (LUZ; ZANIBONI FILHO, 2002), disponibilidade de alimento em seu ambiente (DANIELS; BERLINSKY; SULLIVAN, 1996; BASKERVILLE-BRIDGES; KLING, 2000; DOU et al., 2003), dentre outros fatores.

Segundo Luz e Portella (2005), algumas espécies de peixes apresentam melhores resultados de crescimento quando estocadas em maiores densidades, possivelmente em relação ao tempo de natação, repouso ou alimentação. Sendo assim, tanto a alta como a baixa densidade podem resultar em elevada variação de tamanho, o que certamente varia com a espécie (CAMPAGNOLO, 2004).

No presente estudo, as maiores densidades avaliadas $\left(1\right.$ e 2 larvas $\left.\mathrm{L}^{-1}\right)$ apresentaram crescimento inferior (2,349 cm e 0,112 g; 2,340 cm e 0,114 g, respectivamente) aos demais tratamentos. Possivelmente, o comportamento dessa espécie em relação a densidades elevadas proporcionou a formação de um lote heterogêneo em virtude da competição decorrente das interações sociais ocorridas no ambiente de cultivo.

Além das densidades elevadas comprometerem o crescimento de muitas espécies de peixes, esse fator pode também afetar negativamente a sobrevivência de espécies que praticam canibalismo, como observado por Luz e Zaniboni Filho (2002) com pós-larvas de P. maculatus. Teoricamente, altas densidades de estocagem não deveriam afetar a sobrevivência, desde que fosse possível suplementar artificialmente todas as necessidades de alimento, oxigênio, qualidade de água, mesmo sendo o crescimento fisiologicamente afetado pelo estresse (ANDRADE et al., 2004). Contudo, Luz e Portella (2005), na larvicultura do trairão H. lacerdae, concluíram que larvas dessa espécie podem ser criadas, durante os primeiros 15 dias de alimentação, na densidade inicial de 90 larvas $\mathrm{L}^{-1}$ sem que isso afete a sobrevivência dos indivíduos.

Nas condições em que o presente trabalho foi realizado, as densidades de estocagem avaliadas não influenciaram a sobrevivência das larvas de mandi P. bristkii , mesmo com a transformação dos dados ( $p>$ 0,05). Verificou-se, durante o período experimental, que as larvas mortas não apresentavam sinais evidentes de agressão, podendo-se considerar a inexistente ocorrência de canibalismo. A ausência de predação pode estar relacionada, portanto, ao ótimo recurso alimentar, pois as larvas apresentaram evidências da ingestão de náuplios de Artemia sp, como corpo alaranjado nos primeiros dias de alimentação, o que mostra boa aceitação desse alimento. Dessa forma, a utilização de alimento natural, bem como o fornecimento de alimento inerte de forma gradativa, pode ter contribuído para as elevadas taxas de sobrevivência ( $85 \%$ a $98 \%$ ) obtidas.

A eficiência da utilização de dietas artificiais como fonte de alimentação de pós-larvas de peixes foi constatada por Carvalho et al. (1997), para Cyprinius carpio, e por Hayashi et al. (1998), para Prochilodus lineatus, e a combinação de dietas naturais e artificiais pode proporcionar a redução do canibalismo (PIENAAR, 1990), bem como permitir um desenvolvimento mais homogêneo e maior sobrevivência (FEIDEN et al., 2005).

Analisando os resultados obtidos para o fator de condição, observou-se que esse parâmetro não foi influenciado pelas diferentes densidades de estocagem avaliadas ( $\mathrm{p}>0,05)$, com valores médios variando de 0,832\% a 0,883\% (Tabela 2). Esses resultados indicam que o mandi P. britskii apresentou uma condição de crescimento semelhante para as diferentes densidades avaliadas.

Em relação à taxa de crescimento específico, observaram-se diferenças significativas entre os tratamentos, sendo os melhores resultados obtidos para a densidade de 0,5 larvas $\mathrm{L}^{-1}(19,114 \%)$, apesar desta não diferir significativamente da densidade de 0,25 larvas $\mathrm{L}^{-1}(19,000 \%)$. Adicionalmente, resultados inferiores foram obtidos para as densidades de estocagem mais elevadas (1 e 2 larvas $\mathrm{L}^{-1}$ ) com valores médios de 17,615\% e 17,654\%, respectivamente. Luz e Portella (2005) observaram em seu estudo que o aumento da densidade de estocagem (10 a 90 larvas $\left.\mathrm{L}^{-1}\right)$, apesar de não diferir significativamente entre tratamentos, promoveu uma redução nos valores da taxa de crescimento específico na larvicultura do trairão $H$. lacerdae. Esses autores encontraram valores que variaram de 17,56\% a 21,74\% aos 12 dias de experimento, valores esses próximos ao observados na presente pesquisa.

Semelhantemente, Luz e Santos (2008), avaliando diferentes densidades de estocagem na larvicultura do pacamã Lophiosilurus alexandri, constataram uma redução na taxa de crescimento específico com o aumento da densidade de estocagem aos cinco dias de experimento. Segundo Jobling (1994), altas densidades de estocagem ocasionam problemas de espaço que podem afetar a taxa de crescimento dos peixes.

Rev. Acad., Ciênc. Agrár. Ambient., Curitiba, v. 8, n. 4, p. 389-396, out./dez. 2010 
Dessa forma, quando da escolha de uma nova espécie de criação, é muito importante que se realizem estudos de densidade de estocagem, a fim de se avaliar o efeito desse manejo sobre o crescimento (LUZ; PORTELLA, 2005) e o desempenho dos animais.

\section{Conclusão}

A utilização de larvas de mandi-pintado estocadas na densidade de 0,5 larvas $\mathrm{L}^{-1}$ proporcionou maior desenvolvimento em relação ao peso final, comprimento final e taxa de crescimento específico e as diferentes densidades não afetam a sobrevivência e o fator de condição dos animais.

\section{Referências}

AGOSTINHO, A. A. et al. Reservatório de Salto Caxias: bases ecológicas para o manejo. Maringá: UEM; Nupélia; Copel, 2002.

AMARAL, M. V. C. et al. Diferentes densidades de estocagem na criação de lambari do rabo amarelo em sistema intensivo. In: ENCONTRO LATINO AMERICANO DE INICIAÇÃO CIENTÍFICA, VIII ENCONTRO LATINO AMERICANO DE PÓS-GRADUAÇÃO, 12., 2008, São José dos Campos. Anais... São José dos Campos: Universidade do Vale do Paraíba, 2008.

ANDRADE, L. S. et al. Canibalismo entre larvas de pintado Pseudoplatystoma corruscans cultivadas sob diferentes densidades de estocagem. Revista Acta Scientiarum Biological Sciences, v. 26, n. 3, p. 299-302, 2004.

BASKERVILLE-BRIDGES, B.; KLING, L. J. Larval culture of Atlantic cod (Godus morbua) at high stocking densities. Aquaculture, v. 181, p. 61-69, 2000.

BOYD, C. Water quality in ponds for aquaculture. Alabama: Birmingham Publishing, 1990.

BRANDÃO, F. R. et al. Densidade de estocagem de mantrinxã (Brycon amažnicus) na recria em tanque-rede. Revista Pesquisa Agropecuária Brasileira, v. 40, n. 3, p. 299-303, 2005.

CAMPAGNOLO, R. Larvicultura do surubim Pseudoplatystoma corruscans (Pisces, Pimelodidae), em diferentes densidades de estocagem e fotoperíodos. 2004. 60 f. Dissertação (Mestrado em Aquicultura) - Universidade Federal de Santa Catarina, Florianópolis, 2004.

CAMPAGNOLO, R.; NUÑER, A. P. O. Sobrevivência e crescimento de larvas de surubim, Psendoplatystoma corruscans (Pisces, Pimelodidae), em diferentes densidades de estocagem. Revista Acta Scientiarum Animal Sciences, v. 28, n. 2, p. 231-237, 2006.

CARVALHO, A. P. et al. First feeding of common carp larvae on diets with high levels of protein hydrolysates. Aquaculture International, v. 5, n. 4, p. 361-367, 1997.

DANIELS, H. V.; BERLINSKY, D. L.; SULLIVAN, C. V. Effects of stocking density, salinity, and light intensity on growth and survival of Southern flounder Paralichthys lethostigma larvae. Journal of the World Aquaculture Society, v. 24, p. 153-159, 1996.

DOU, S. et al. Identification of factors affecting the growth and survival of the settling Japanese flounder larvae, Paralichthys olivaceus. Aquaculture, v. 218, p. 309-327, 2003.

FEIDEN, A. et al. Desenvolvimento do surubim do Iguaçu (Steindachneridion sp; Garavello (1991)) (Siluroidei: Pimelodiae) em ambiente escuro durante a fase inicial, alimentado com diferentes dietas. Revista Semina: Ciências Agrárias, v. 26, n. 1, p. 109-116, 2005.

FEIDEN, A.; HAYASHI, C.; BOSCOLO, W. R. Desenvolvimento de larvas de surubim-do-iguaçu (Steindachneridion melanodermatum) submetida a diferentes dietas. Revista Brasileira de Zootecnia, v. 35, n. 6, p. 2203-2210, 2006.

Rev. Acad., Ciênc. Agrár. Ambient., Curitiba, v. 8, n. 4, p. 389-396, out./dez. 2010 
GARAVELlO, I. C.; SHIBATTA, O. A. A new species of the genus Pimelodus La Cépède, 1803 from the rio Iguaçu basin and a reappraisal of Pimelodus ortmanni Haseman, 1911 from the rio Paraná system, Brasil (Ostariophysi: Siluriforme: Pimelodidae). Neotropical Ichthyologii, v. 5, n. 3, p. 285-292, 2007.

HAYASHI, C. et al. Plâncton e dieta artificial na alimentação do "curimbatá" (Prochilodus lineatus), na fase inicial. In: SIMPÓSIO BRASILEIRO DE AQUICULTURA, 10., 1998, Recife. Anais... Recife: ABRAQ, 1998. p. 25.

HATZIATHANASIOU, A. et al. Survival, growth and feeding in early life stages of European sea bass (Dicentrarchus labrax) intensively cultured under different stocking densities. Aquaculture, v. 205, n. 1/2, p. 89-102, 2002.

JOBLING, M. Fish bioenergetics. London: Chapman \& Hall, 1994.

JOMORI, R. K. et al. Growth and survival of pacu Piaractus mesopotamicus (Holmberg, 1887) juveniles reared in ponds or at different initial larviculture periods indoors. Aquaculture, v. 221, n. 1, p. 277-287, 2003.

KESTEMONT, P. et al. Size heterogeneity, cannibalism and competition in culture predatory fish larvae: biotic and abiotic influences. Aquaculture, v. 227, n. 1/4, p. 333-356, 2003.

KRUMMENAUER, D. et al. Viabilidade do cultivo do camarão-rosa Farfantepenaeus paulensis (Crustácea, Decapoda) em gaiolas sob diferentes densidades durante o outono no sul do Brasil. Ciência Rural, v. 36, n. 1, p. 252-257, 2006.

LUZ, R. K. Aspectos da larvicultura do trairão Hoplias lacerdae: manejo alimentar, densidade de estocagem e teste de exposição ao ar. 2004. 133 f. Tese (Doutorado em Aquicultura) - Universidade Estadual Paulista, Jaboticabal, 2004.

LUZ, R. K.; PORTELLA, M. C. Diferentes densidades de estocagem na larvicultura do trairão Hoplias lacerdae. Revista Acta Scientiarum Biological Sciences, v. 27, n. 1, p. 95-101, 2005.

LUZ, R. K.; SANTOS, J. C. E. Densidade de estocagem e salinidade da água na larvicultura do pacamã. Revista Pesquisa Agropecuária Brasileira, v. 43, n. 7, p. 903-909, 2008.

LUZ, R. K.; ZANIBONI FILHO, E. Utilização de diferentes dietas na primeira alimentação do mandi-amarelo (Pimelodus maculatus, Lacépède). Revista Acta Scientiarum, v. 23, n. 2, p. 483-489, 2001.

LUZ, R. K.; ZANIBONI FILHO, E. Larvicultura do mandi-amarelo Pimelodus maculatus Lacépède, 1803 (Siluriformes: Pimelodidae) em diferentes densidades de estocagem nos primeiros dias de vida. Revista Brasileira de Zootecnia, v. 31, n. 2 , p. $560-565,2002$.

PIEDRAS, S. R. N.; POUEY, J. L. O. F.; MORAES, P. R. R. Comportamento alimentar e reprodutivo de peixes exóticos e nativos cultivados na zona sul do Rio Grande do Sul. Revista Brasileira de Agrociência, v. 12, n. 3, p. 341-344, 2006.

PIENAAR, A. G. A. Study of coeval sibling cannibalism in larval and juvenile fishes and its control under culture conditions. 1990. 162 f. Thesis (Masters) - Rhodes University, Grahamstown, 1990.

URBINATI, E.; CARNEIRO, P. C. F. Práticas de manejo e estresse dos peixes em piscicultura. In: CYRINO, J. E. P. et al. Tópicos especiais em piscicultura de água doce tropical intensiva. São Paulo: TecArt, 2004.

WEINGARTNER, M.; ZANIBONI FILHO, E. Efeito de fatores abióticos na larvicultura de pintado amarelo Pimelodus maculatus (Lacépède, 1803): salinidade e cor do tanque. Revista Acta Scientiarum Animal Sciences, v. 26, n. 2, p. 151-157, 2004.

Recebido: 01/12/2009

Received: 12/01/2009

Aprovado: $12 / 08 / 2010$

Approved: 08/12/2010

Rev. Acad., Ciênc. Agrár. Ambient., Curitiba, v. 8, n. 4, p. 389-396, out./dez. 2010 